\title{
Nationalism and gender in the representation of non-Japanese characters' speech in contemporary Japanese novels
}

\author{
Satoko Suzuki \\ Macalester University, United States
}

This study demonstrates that two types of language ideologies (linguistic nationalism and feminine language normativity) influence how Japanese contemporary novels represent non-Japanese characters' speech. It investigates the role of gender and observes that novelists only infrequently assign highly gendered utterance-final forms to non-Japanese characters when they speak in Japanese. This tendency is more salient among the representations of male non-Japanese characters. Masculine expressions seem to belong to a set of linguistic resources that are considered available only to the Japanese. This exclusivism, i.e., linguistic nationalism, might explain the lack of highly masculine forms among non-Japanese characters in novels. As for the relatively frequent assignment of gendered language for female characters, the normativity of feminine language makes it part of the basic language of all female speakers including non-Japanese individuals. In addition, feminine expressions are not as strongly associated with authenticity as masculine expressions.

Keywords: language ideologies, linguistic nationalism, normativity, representation, gender, femininity, masculinity, Japanese

\section{Introduction}

\subsection{Language ideologies}

In his chapter on language ideologies, Paul V. Kroskrity writes the following:

Just as modes of cultural representations have been reshaped by a confrontation with the increasing complexity of the sociocultural world so, too, linguistic anthropologists have turned to language ideological perspectives as an increasingly important means of understanding this complexity and the way that speakers, groups, and governments use languages - and their ideas about languages - to create and negotiate those sociocultural worlds.

(Kroskrity 2004, 512) 
The chapter summarizes as well as advocates research on language ideologies. Broadly defined, language ideologies are "beliefs, or feelings, about languages as used in their social worlds" (Kroskrity 2004, 498). More specifically, language ideology refers to a "cultural system of ideas about social and linguistic relationships, together with their loading of moral and political interests" (Irvine 1989, 255).

Investigations of language ideologies have produced significant and diverse scholarship. Johnson and Milani (2010) summarizes the aim of language ideology research as investigating "how linguistic phenomena are invested with meanings and values though the production, reproduction and/or contestation of conventional indexical ties between (i) perceived or presumed features, genres, styles or varieties of language and (ii) broader cultural representations of their purported speakers in terms of nationality, ethnicity, gender, sexuality, aesthetics, morality and so forth" (Johnson and Milani 2010, 4).

Language ideologies have been of central concern to many scholars who investigate Japanese language and society. For example, Yi Yŏn-suk’s book (1996) "Kokugo" to yuu shisoo: Gendai nihon no gengo ninshiki 'The Ideology of "National Language": Language Cognition in Modern Japan' examined the history and ideology behind the construction of kokugo 'national language' in Japan. More recently, Shigeko Okamoto and Janet Shibamoto Smith's book (2004), Japanese Language, Gender, and Ideology: Cultural Models and Real People, is a collection of articles that investigate how ideologies regarding language and gender influence linguistic practices and representations. Shinji Sato and Neriko Doerr's book (2008), Bunka, kotoba, kyooiku: Nihongo/ Nihon no kyooiku no "hyoojun" o koete 'Culture, Language, Education: Beyond the "Standard" of Japanese Language/Japan Education' discusses how ideologies regarding language, culture, and society interact with educational practices.

This study investigates the impact of language ideologies on the representations of non-Japanese characters' speech in Japanese contemporary novels, and contributes to this growing scholarship on language ideologies in Japan.

\subsection{Why study representations?}

Examining how language is represented in various media such as novels, magazines, television dramas, films, and Internet would allow us to not only consider indexical ties between linguistic phenomena and axes of social categorizations (i.e., language ideologies), but also "look more precisely at the ways in which such ties are created, naturalized and/or contested" (Johnson and Milani 2010, 8). As the following examples show, representations in the media have the power to invent, establish and disseminate language ideologies. 
Kumagai (2010) observes that by assigning Tohoku-ben (a dialect spoken in Northeastern Japan) to the speech of fictional characters such as servants, ethnic minorities and lower class characters in Western novels and television dramas, the Japanese translations of their dialogs have created and perpetuated a stigmatized image of the dialect (see also Inoue (2003) and Hiramoto (2009)). She also notes that romantic heroines of television dramas that are based in regional Japan may speak regional dialects, but never Tohoku-ben, thus reproducing the ideology that only the peripheral, non-beautiful, and unsophisticated speak Tohoku-ben (see also Shibamoto Smith and Occhi 2009). ${ }^{1}$

Inoue (2004) and Nakamura (2006) observe that in the early twentieth century so-called school-girl speech, which contemporaneous intellectuals initially characterized as vulgar, was ascribed increasingly in domestic novels and magazines to middle and/or upper-middle class women. Because this representation was repeatedly presented to consumers, the sentence-final particles that were associated with school-girl speech evolved to become features of feminine, refined speech. The ideology of linking these sentence-final particles and femininity remains today.

Kinsui (2003) and Chinami (2010) note that through sustained exposure to metapragmatic stereotypes ${ }^{2}$ in fiction, individuals often learn and internalize such stereotypes, which Kinsui (2003) calls yakuwari-go 'role language.' Kinsui $(2014,13)$ observes that learners of the Japanese language who study outside of Japan score only 60 to 70\% when tested on the knowledge of yakuwari-go. He also reports that children who grow up in Japan would acquire the knowledge, which is part of their language ideologies, by the age of 4 or 5 through their repeated exposure to stereotypes in picture books, children's literature, television, video, and so on.

In the introduction to their book on Japanese language, gender, and ideology, Okamoto and Shibamoto Smith $(2004,11)$ write the following:

1. The drama called "Amachan," which was broadcast in 2013 on the national television network, NHK, on the surface seems to be the exception. The heroine, Aki Amano, speaks Tohoku-ben. However, the drama does not depict her as an authentic Tohoku-ben speaker. She is a Standard Japanese speaker who supposedly adopts Tohoku-ben when she moves there at the age of 16 . Aki as well as other characters in the drama call attention to the fact that she is a nise hoogen hiroin 'fake dialect heroine' (Tanaka 2014, 34). Kumagai (2016) notes that Aki repeatedly and exaggeratedly uses limited Tohoku-ben expressions and misuses or overuses certain case markers and sentence-final particles. Tanaka (2014) calls such metalinguistic performance as hoogen kosupure "dialect costume play.' Kumagai (2016) also observes that Aki does not use Tohoku-ben when talking with her boyfriend, which reflects the ideology that Tohoku-ben is inappropriate for a romantic heroine.

2. Metapragmatic stereotypes arise when "many persons typify criterial speech forms in the same way, assigning the same metalinguistic predicates (e.g., "is slang," "is polite," "is used by older persons," etc.) to the forms at issue" (Agha 2004, 26). 
An understanding of the media messages Japanese men and women are receiving - about how to be adequate or attractive women and men, about how to view feminine and masculine social roles, about how to construe love and marriage - is critical to an understanding of the ongoing production, reproduction, and transformation of gender relations. [...] In a variety of ways, print and other media have the power to establish ideas about what constitutes desired femininity and masculinity with respect to personality traits, behaviors, and so on. ${ }^{3}$

Similarly, representations of non-Japanese speech in fiction such as novels have the power to establish ideas about foreignness. Non-Japanese individuals may not consume Japanese novels as much as the Japanese do and thus the possibility of their internalization of those ideas may be small, but the novels do influence the Japanese readers' expectations about how non-Japanese individuals behave linguistically or otherwise. By reading novels and thereby being exposed to their "covert prescriptions" (Okamoto and Shibamoto Smith 2004, 11), the Japanese readers take the legitimacy of the cultural models for non-Japanese individuals for granted.

\subsection{Why study the speech of non-Japanese characters?}

The quote from Kroskrity (2004) at the beginning of this introduction mentions the importance of language ideological perspectives in the age of an increasingly complex world. As noted by a number of scholars (e.g. Tsuneyoshi 2004; Okubo 2010; Sugimoto 2014), Japan has been undergoing significant demographic changes. Although the number of foreign residents in Japan is still relatively small (less than $2 \%$ ), the number has more than doubled from about 1.1 million in 1990 to about 2.4 million in 2016 (Ministry of Justice). Sugimoto $(2014,197)$ observes, "Grassroots Japan is undergoing a process of irreversible globalization."

Against this background of Japan's increasing demographic diversity, it is especially pertinent to examine how non-Japanese individuals' language is portrayed in media. As mentioned above, media have the power to influence Japanese consumers' ideas. Hagiwara et al. $(2004,77)$ point out that most people gather information

3. Inoue (2003) and Okamoto and Shibamoto Smith (2008) also discuss how repeated implicit messages expressed in print and other media have the power to naturalize and make the recipients internalize gender ideologies.

4. This does not mean that Japan was a demographically homogeneous country before the recent influx of immigrants. Minorities such as Okinawans, Ainu, Burakumin, Koreans, Chinese and other immigrants from Asia have long resided in Japan. The immigrants that came to Japan recently, especially after 1990 when the review of immigration control legislation was carried out, are sometimes called nyuu kamaa ('newcomers'). See Tsuneyoshi (2004), Okubo (2010), and Sugimoto (2014) for discussions of minorities in Japan. 
from the media regarding situations with which they do not have direct experience. Burgess (2010) mentions that less than one in ten Japanese have opportunities to interact with non-Japanese individuals in Japan. This means that the media plays a significant role in the formation of Japanese perceptions of non-Japanese (Hambleton 2011, 32-33).

I have selected to investigate the use of gendered language in the representation of non-Japanese speech. As I will explain in the following section, previous scholarship on non-Japanese speech has lacked perspectives on gender.

This study is concerned with two specific language ideologies that are pertinent to the depiction of non-Japanese speech: linguistic nationalism and normativity of feminine language. Linguistic nationalism in the context of Japanese society is often expressed in propriety terms; only the ethnically Japanese are supposed to own the Japanese language and can speak it competently (Miller 1995; McVeigh 2006; Perkins 2010). Feminine language normativity refers to the expectations of feminine language that society imposes upon female speakers in Japan (Okamoto and Shibamoto Smith 2004; Nakamura 2007, 2013).

\section{Previous scholarship}

Previous studies on how non-Japanese individuals are depicted on visual media such as television shows and commercials include Miller (1995), Creighton (1997), Yano (2004, 2010), Iwabuchi $(2005,2007)$, Perkins (2010), Hambleton (2011), Ota (2011), Doerr and Kumagai (2014), SturtzSreetharan (2015), and Suzuki (2015). Among these, Miller (1995), Yano (2004), Perkins (2010), SturtzSreetharan (2015), and Suzuki (2015) discuss how the Japanese language that non-Japanese individuals speak has been portrayed on television.

In the sphere of print media, previous studies on how non-Japanese individuals are depicted speaking Japanese include Kinsui $\left(2003,{ }^{5} 2007,2008\right)$ and Yoda (2011). Many more studies, including Shibamoto Smith (2005), Yoda (2007), Hiramoto (2009), Hasegawa (2012), and Nakamura (2013), investigate how non-Japanese individuals' speech is translated into Japanese from other languages such as English. This study, however, as well as Kinsui $(2003,2007,2008)$ and Yoda (2011), is concerned with how print media represent the speech of non-Japanese individuals who communicate in Japanese.

5. Kinsui (2003) is a comprehensive study that analyzes fictional speech in general. One chapter details the historical developments of the varieties of Pidgin Japanese that have been associated with Chinese speakers. 
Among the scholarship that examines print media representations of nonJapanese individuals' speech in Japanese, Yoda (2011) most comprehensively investigates the depiction of non-Japanese characters' speech in contemporary Japanese media. Her purpose is to examine how fiction creators represent metapragmatic stereotypes of non-Japanese individuals. For this reason, she focuses her attention on comic books and animation films. As Kinsui (2003) observes, metapragmatic stereotypes figure most prominently in comic books and children's literature. Creators of these genres tend to construct simplistic (and not nuanced or complex) characters and thus utilize exaggerations and stereotypes. Yoda (2011) finds, among other things, that in comic books and animation films non-Japanese speech is constructed as katakoto nihongo 'fragmented, broken Japanese' and that the formality of sentence endings is correlated with the race of non-Japanese characters.

The data examined in this study are contemporary novels for adult consumption and are substantially different from Yoda's data. The metapragmatic stereotypes discussed in Yoda (2011), which are sometimes quite blatant, do not figure prominently in the depiction of non-Japanese speech in contemporary novels. This is to be expected since authors writing novels for adult audiences create more nuanced and multi-dimensional characters and do not necessarily depend on conventional stereotypes.

This study, however, demonstrates that contemporary novelists do demonstrate some prejudices regarding gender, which Yoda (2011) does not discuss. Japanese is well known for having linguistic expressions distinctly associated with femininity and masculinity. This study has found that novelists tend not to assign gendered utterance-final expressions to non-Japanese characters. However, relatively speaking, novelists do assign gendered forms to non-Japanese female characters much more frequently than to male characters. I will relate these findings to two types of language ideologies: linguistic nationalism and feminine language normativity, respectively.

Not only Yoda (2011), but also other works on the Japanese speech of nonJapanese characters in fiction pass over the issue of gender in their analyses, ${ }^{6}$ although a number of studies that examine non-Japanese characters' speech in translation investigate the relation between gender and translation (e.g., Inoue 2003; Shibamoto Smith 2005; Nakamura 2013). What has been lacking is the analysis of non-Japanese individuals' fictional speech in Japanese and gender. This study fills the gap.

This study also contributes to the research on media representations of gendered language in Japan. Many previous studies (e.g., Kinsui 2003; Shibamoto Smith 2004; Inoue 2006; Chinami 2006, 2010; Mizumoto 2006, 2010; Okamoto and Shibamoto Smith 2008; Shibamoto Smith and Occhi 2009; Occhi, Shibamoto-Smith

6. Kinsui (2003) extensively discusses stereotypes in gendered language of Japanese characters, but does not mention gender in relation to non-Japanese characters. 
and SturtzSreetharan 2010; Hiramoto 2010) have helped us understand the relationship between gender and language in the fictional depictions of Japanese characters in various media such as novels, comics, essays, and television dramas. This study, by analyzing the representation of non-Japanese characters' speech in novels, provides a different perspective and adds to the body of scholarship.

\section{Data}

Although a recent survey conducted by the government (Bunkachoo 2014) found Japanese adults are reading increasingly fewer books, other indications show that Japan still has a rich reading culture. UNESCO rates Japan's adult literacy at 99\% (UNESCO). The Japan Times editorial declared that public libraries are thriving by reporting that the total number of books checked out at public libraries was 663.6 million nationwide ("Public Libraries Are Thriving"). Alvin Lu, general manager of San Francisco's Kodansha Advanced Media, says, "The population of Japan is about a third of the US, but the [size of the] book market is comparable" (Publishing Perspectives). About 3,700 publishing companies generate about $¥ 1.7$ trillion worth of business annually (Japan Book Publishers Association 2014). In discussing Japan’s built-in audience for reading on the phone, Lu also says, "This had a lot to do with Japan's train culture and also its very large book culture. It's a culture that reads."

If Japan is indeed a culture that reads, then investigating what is written in books would be a meaningful endeavor because of their influence in society. I have chosen to examine the speech of 123 non-Japanese characters found in 31 contemporary novels. ${ }^{7}$ By contemporary novels, I mean novels that have been published in the last 25 years. Contemporary novels may be divided into many genres such as romance, mystery, science fiction, business novels, horror, action, historical fiction, and light novels. ${ }^{8}$ Since I needed to select novels that have non-Japanese characters in them and thus had to search broadly, I did not focus on one genre. While the 31 books I have used include some romance, action, and mystery novels, it is difficult to specifically categorize some of the novels. Novels that involve romantic stories such as Ekuni (1999, 2013); Kawataki (1993); Murayama (2000, 2012); Yamada (1993); and Tsuji $(1999,2002)$ may be targeted towards a female audience while

7. The data references Appendix lists the titles of the novels.

8. See Shibamoto Smith and Schmidt (1996) for descriptions of these genres except for action, horror and light novels. Light novels, or raito noberu, are Japanese novels primarily aimed at junior high and high school students. Kadokawa Publisher's 2012 annual report says, "light novels are a form of entertainment that specialize in characters and make extensive use of illustrations" (Kadokawa Group Holdings, Inc. 2012, 11). 
novels that feature action such as Fukui (2002); Ishida (2001); Kakine (2009); and Yanagi $(2008,2012)$ may be aimed at male readers. However, other books do not seem to be marketed to particular audiences. Of the 31 novels, 19 are written by 16 male authors, and 12 by 10 female authors.

I collected the titles of these 31 novels in which non-Japanese characters appear by using an Internet search engine ${ }^{9}$ and by surveying a parent network at a Japanese immersion school in a Midwestern city in the United States. ${ }^{10}$ Although certain authors have written multiple novels in which non-Japanese characters appear, I avoided using more than two novels by the same author.

I found 53 characters depicted speaking in Japanese and 77 characters speaking in other languages. ${ }^{11}$ I am primarily concerned with the first set of characters, i.e., characters speaking in Japanese, but I also examined the second set of characters for comparison.

\section{Gender and non-Japanese characters' speech}

This section illustrates how non-Japanese characters' speech is depicted in an unbalanced manner with regard to gendered language. As mentioned earlier, Japanese has linguistic expressions distinctly associated with femininity and masculinity. They include pitch, vocabulary, referential forms, and utterance-final expressions. Recent scholarship on the speech of real (as opposed to fictional) speakers (e.g., Okamoto and Shibamoto Smith 2004; Sreetharan 2004; Inoue 2006; Nakamura 2007) observes that the use and non-use of these expressions are fluid and motivated by multiple factors.

In this paper I focus on the relationship between non-Japanese characters' speech and gendered utterance-final expressions. Okamoto and Sato (1992, 480-481) categorize the following utterance-final expressions as strongly feminine and masculine forms: ${ }^{12}$ These gender associations are based on stereotypes and not on actual usages.

9. I searched for "novels in which foreign characters appear" and found the following website: http://detail.chiebukuro.yahoo.co.jp/qa/question_detail/q11112842916 (Accessed August 31, 2014).

10. I used this parent network, the group of Japanese novel readers accessible to me, so that the selection of the novels does not solely depend on my own knowledge and on the information gained from the website, which is likely based only on the website creator's knowledge.

11. The sum of the characters is 130 rather than 123 because there are 7 characters who speak both in Japanese and in another language.

12. Okamoto and Sato (1992) also discuss moderately feminine and masculine forms, but I am not including them in my examination of the data. 
1. Strongly feminine forms
a. The particle wa for mild emphasis.
b. The particle wa followed by ne, yo, or yo ne.
c. The particle wa preceded by da or datta.
d. The particle wa preceded by da or datta and followed by ne, yo, or yo ne.
e. The particle yo attached after a noun or na-adjective.
f. The particle no after a noun or $n a$-adjective in a statement.
g. The particle no followed by ne, yo, or yo ne.
h. The form kashira 'I wonder.'

2. Strongly masculine forms
a. The particle $z o$ and $z e$.
b. The plain imperative form of a verb by itself or followed by yo.
c. The particle na or na yo for a negative command.
d. The particle na for eliciting agreement.
e. The phonological form ee istead of $a i$ and $o i$.
f. The form ka yo for expressing defiance or criticism.

Table 1 shows the percentages of the assignment and non-assignment of these strongly gendered forms in my data of non-Japanese characters' speech in Japanese.

Table 1. Gendered utterance-final form assignment when characters speak in Japanese

\begin{tabular}{lccc}
\hline & $\begin{array}{l}\text { Gendered utterance-final } \\
\text { forms present }\end{array}$ & $\begin{array}{l}\text { Gendered utterance-final } \\
\text { forms absent }\end{array}$ & Total \\
\hline female characters & $9(56 \%)$ & $7(44 \%)$ & 16 \\
male characters & $5(14 \%)$ & $32(86 \%)$ & 37 \\
both sexes & $14(26 \%)$ & $39(74 \%)$ & 53 \\
\hline
\end{tabular}

The table shows that the assignment of strongly feminine and masculine forms is not very prevalent in the non-Japanese characters' speech in Japanese (present only $26 \%$ of the time), especially in the portrayal of male speech (present only $14 \%$ of the time). ${ }^{13}$ This result by itself is not especially remarkable. However, when you compare this with the percentages of the assignment and non-assignment of the gendered forms in the non-Japanese characters' speech when they speak a different language, the contrast is striking.

In a Japanese novel, when a character speaks in a language other than Japanese, the utterances could be represented in the original language or in Japanese. In all of the novels I examined, non-Japanese utterances are rendered in Japanese,

13. The assignment of gendered language to female characters is more frequent at $56 \%$. I will address this in Section 6. 
presumably so that Japanese readers understand them. ${ }^{14}$ Contexts make it clear that another language is used in such scenes. In these 'translated' utterances, ${ }^{15}$ gendered utterance-final forms abound as shown in Table 2.

Table 2. Gendered utterance-final form assignment when characters speak in another language

\begin{tabular}{llll}
\hline & $\begin{array}{l}\text { Gendered utterance-final } \\
\text { forms present }\end{array}$ & $\begin{array}{l}\text { Gendered utterance-final } \\
\text { forms absent }\end{array}$ & Total \\
\hline female characters & $25^{16}(96 \%)$ & $1(4 \%)$ & 26 \\
male characters & $42^{17}(82 \%)$ & $9(18 \%)$ & 51 \\
both sexes & $67(87 \%)$ & $10(13 \%)$ & 77 \\
\hline
\end{tabular}

The percentage differences of gendered utterance-final form assignment when characters speak in Japanese and when they speak in another language are quite remarkable. When characters use Japanese, gendered utterance-final forms are used only $26 \%$ of the time. When they are depicted talking in another language, gendered forms are used $87 \%$ of the time. Thus, gendered forms are prevalent only when languages other than Japanese are used. In the following two sections, I will relate these results to the notions of linguistic nationalism and feminine language normativity.

\section{Linguistic nationalism and the lack of gendered forms in male non-Japanese characters' speech in Japanese}

Table 3 recapitulates the contrast of gendered form assignment between when characters speak Japanese and when they speak in another language.

14. There are novels in which non-Japanese utterances are rendered in the original languages. It would be interesting to explore what effects such a multilingual writing creates, but it is beyond the scope of this study.

15. These utterances have not been actually translated since they were never written in the original language in the first place.

16. 2 out of these 25 female characters use strongly masculine forms rather than strongly feminine forms. See Okamoto (1995) and Nakamura (2007) for discussion of female speakers' use of masculine language.

17. 1 out of these 42 male characters uses strongly feminine forms rather than strongly masculine forms. This character uses what is often called onee kotoba, hyper feminine language stereotypically associated with gay men (Ogawa \& Smith 1997; Maree 2008; Abe 2010). Maree suggests that onee kotoba "can be read as a negotiative practice that resists and desists the coercive heteronormative language styles that are "women's language" and "men's language"” (Maree 2008: 75). 
Table 3. Gendered utterance-final form assignment in Japanese and in another language

\begin{tabular}{lcl}
\hline & $\begin{array}{l}\text { Gendered utterance-final form } \\
\text { assignment in Japanese }\end{array}$ & $\begin{array}{l}\text { Gendered utterance-final form } \\
\text { assignment in another language }\end{array}$ \\
\hline female characters & $9 / 16(56 \%)$ & $25 / 26(96 \%)$ \\
male characters & $5 / 37(14 \%)$ & $42 / 51(82 \%)$ \\
both sexes & $14 / 53(26 \%)$ & $67 / 77(87 \%)$ \\
\hline
\end{tabular}

As mentioned earlier, the contrast between the infrequent assignment of gendered forms when characters speak in Japanese and the frequent assignment when they speak in another language is even sharper among male characters. When male characters speak Japanese, they are given gendered utterance-final forms only $14 \%$ of the time while the percentage is $82 \%$ (almost a 6 -fold difference) when they speak in another language. I will focus on this intriguing phenomenon in this section.

The following examples illustrate the assignment and non-assignment of masculine utterance-final forms to male characters. The expressions associated with masculinity are marked in bold.

(3) Chika, ame da zo. [...] Kitsui ichinichi ni narisoo da na. $<$ name $>$ rain $\mathrm{COP}^{18} \mathrm{FP}$ hard one:day to get:look COP FP 'Chika, it is raining. [...] It looks like it is going to be a hard day, doesn't it?'

(Kondo 2010, 63-64)

(4) Tsu, tsumetee! [...] Kaisuiyoku, kore de owari ka yo? [...] Tatta $c$ cold swim:at:beach this with end FP FP only kono gobyoo no tameni, orera, ketsu ga itakunaru no this five:seconds GEN for we ass NOM hurt: hurt NMLZ o gamanshite, konna tokoro made kita no ka yo! ACC endure this.kind place until came NMLZ FP FP 'C-cold! [...] That's it for swimming at the beach already? [...] Did we put up with the pain in the ass and come all the way here just for these 5 seconds?

(Yoshida 2012, 122)

18. The following abbreviations will be used:

$\begin{array}{llll}\text { ACC } & \text { accusative } & \text { NMLZ } & \text { nominalizer } \\ \text { COND } & \text { conditional } & \text { NOM } & \text { nominative } \\ \text { COP } & \text { copula } & \text { PASS } & \text { passive } \\ \text { FP } & \text { final particle } & \text { QUOT } & \text { quotative } \\ \text { GEN } & \text { genitive } & \text { TOP } & \text { topic } \\ \text { NEG } & \text { negative } & & \end{array}$


(5) Anata wa jibun ga donnani miryokuteki na josei $k a$, you TOP self NOM how attractive COP woman FP wakatteiru $n$ desu ka. [...] Boku wa itsudemo matteimasu kara. understand NOM COP FP I TOP any:time be:waiting so 'Do you realize what an attractive woman you are? [...] I will be there for you any time.'

(Ekuni 2013, 216-217)

(6) Moo ii. Moo yamete kudasai. Boku no kosei wa, boku already fine already stop please I GEN character TOP I no ryooshin de sae hihan dekinai. Darenimo, boku no GEN parents COP even criticize can: NEG nobody I GEN kosei o hihansuru kenri nante nai. character ACC criticize right TOP exist.NEG 'Enough. Please stop it already. Even my parents cannot criticize my character. Nobody has the right to criticize my character.'

(Miyamoto 1998, 269)

In (3) and (4) non-Japanese characters are talking in a language other than Japanese. A Finnish character speaking in French says (3), which contains the particles $z o$ and $n a$, both of which are strongly associated with masculinity. In (4), a Taiwanese character speaking in Mandarin ${ }^{19}$ pronounces an adjective tsumetai 'cold' as tsumetee, which is linked to masculinity. He also uses the highly gendered utterance-final expression $k a$ yo. In addition, he uses the referential form orera (a plural form of ore, the first person pronoun associated with roughness and strong masculinity) as well as a vulgar expression ketsu 'ass.'

In contrast, (5) and (6) illustrate that non-Japanese characters' speech in Japanese tends to lack any gender markers. An American speaking in Japanese in (5) uses formal sentence endings, which are devoid of gender. A Hungarian in (6) speaks informally, but still does not use any of the strongly masculine forms.

Why do the depictions of non-Japanese characters' speech in Japanese lack gendered utterance-final forms? Also, why is this tendency especially salient in the portrayals of non-Japanese male speech? It is as if the novelists linguistically emasculate male characters when they speak Japanese.

One possible explanation is that almost half of the non-Japanese characters speak what Yoda (2011) calls katakoto nihongo 'broken Japanese'. If characters are speaking in fragmented, ungrammatical Japanese, you would not expect them to incorporate gender in their language. Of the 37 male characters who speak Japanese, 14 speak fragmented, ungrammatical Japanese. Among these incompetent speakers, only 1 speaker (7\%) is depicted using masculine forms. However, this

19. The novel actually does not explicitly say which language the character is speaking, but he is speaking in his native language and not in Japanese. My colleague in Chinese Studies in my institution, Rivi Handler-Spitz, informs me that young people in Taiwan are likely to be speaking in Mandarin, but it depends on multiple factors such as the speaker's region, language ideology, etc. 
explanation does not account for many cases in which a character speaks fluently and in a gender-less manner. Of the 37 male characters who speak Japanese, 23 speak excellent Japanese. Among these competent speakers, only 4 characters (17\%) are assigned masculine utterance-final forms. ${ }^{20}$

Another potential explanation is related to the particular contexts in which gendered language tends to appear. As Okamoto and Sato (1992) and Nakamura (2007) observe, gendered expressions are more likely to occur in informal conversations among people who are close to each other. It would be reasonable to assume that non-Japanese characters would use Japanese when interacting with native Japanese characters. Since non-native and native characters are more likely to be distant from each other (given that they likely come from different countries) than among native speakers, their language might be more formal and thus would lack gender markers. However, there are many exceptions to this account. For example, the American character in (5) above, Kenny Jones, is talking to his lover immediately after multiple intercourses. One could not detect such intimacy from his linguistic formality. He comes across as inappropriately polite.

Thus, the two potential explanations discussed above are insufficient. In addition to these two factors, something else must play a crucial role. Kenny Jones, the American character discussed above, talks exclusively in a gender-less manner when he speaks Japanese as shown in (5). However, in a scene in which he recalls a brief exchange with his former wife, who is American, his language is gendered as shown in (7). Here he is supposed to be speaking in English.

(7) Baka na koto o yuuna yo. [...] Keitii, keitii,
ridiculous COP thing ACC say: NEG FP
keitii, ochitsuite-kure yo.
<name> calm.down-please FP
'Don't be ridiculous. [...] Katie, Katie, Katie, (please) calm down',

(Ekuni 2013, 100)

In (7) Jones uses a negative imperative form yuu na 'don't say' and an affirmative imperative form ochitsuite kure ${ }^{21}$ '(please) calm down', both of which are associated with strong masculinity. His speech is casual, assertive, and is indicative of their

20. Of the 16 female characters who speak Japanese, 7 speak excellent Japanese while 9 speak fragmented, ungrammatical Japanese. Among the competent speakers, 5 (71\%) use feminine language. Among the incompetent speakers, 4 (44\%) use feminine forms, which is a high percentage. I will discuss the distinction between female and male speech representations in Section 6.

21. Kure is an imperative form of the verb kureru 'give' and is used here as an auxiliary verb. The compound literally means 'Give me the act of calming down.' The politeness level of the utterance is lower than what the English translation 'please calm down' indicates, since kure is an informal command. 
intimacy level. What motivates the novelist to distinguish Jones' Japanese speech (gender-less) from his English speech (gendered)?

In order to understand the motivations of fiction writers, I here turn to research on real (as opposed to fictional) speakers as well as metapragmatic discourses surrounding the Japanese language.

Ohta (1993) reports that one of her fluent non-Japanese interviewees, Rick, found that his Japanese friends did not feel it proper for Rick to use masculine language. He says the following:

(8) When I'd use very colloquial stuff like men would use, they just didn't like it, and this was the people who were using it with me. [They]'d say, "No you don't use that stuff like that." They did not like to hear me speak like that. [...] Maybe they felt obliged to make sure I knew what was the proper Japanese way to say it.

(Ohta 1993, 219)

Similarly, in interview data reported in Iwasaki (2011) a white male learner who was studying in Japan recounts receiving negative reactions from Japanese peers when he tried to use masculine forms.

Fukuda (2014) also observes a similar reaction by a Japanese individual to a nonJapanese individual's use of masculine Japanese. In a restaurant, a speaker from Mexico, José, says umaai 'tasty' after tasting a dish. Umaai (a lengthened version of umai) is considered to be a part of masculine language (Takasaki 2012). His Japanese companion, Kumiko, says, 'Oh, you say umai' in Japanese, indicating that she was surprised to hear José use a masculine expression. Later on in the conversation Kumiko discusses her preconceived idea that Japanese language learners are limited in their understanding of slang and masculine forms. ${ }^{22}$

22. Itakura (2009), however, reports that her interviewees, male Cantonese speakers who were working in Japanese companies in Hong Kong, were able to use masculine forms to demonstrate proficiency and to build solidarity with their male Japanese peers. This might suggest that race/ ethnicity is another factor in the formation of language ideology surrounding masculine language in Japan. McVeigh $(2006,191)$ observes, "Japanese-speaking Asians, presumably because they "look more Japanese," are not big news. In other words, Japanese speaking ability, as something that is cultural, is often instinctively linked to some inborn Japaneseness that also manifests itself through physical appearance (i.e., racial determinism)." Catherine I-Chung Chang (personal communication) suggests that geographical proximity might also play a role. In addition, one of the reviewers for this article informs, "In anthropological fieldwork reports in the past we learned that foreign men who hang out with working class Japanese men speak highly gendered masculine Japanese, but still might have actually poor linguistic competence. So there is a class aspect to the forms of language a foreigner uses." Thus, multiple factors influence the linguistic behavior of non-Japanese individuals in real life. It is beyond the scope of this study to discuss multifarious situations of actual language use. 
Kumiko's idea might come from how educators view masculine forms. Iwasaki (2011) observes that Japanese language teachers and textbook authors think learners should speak politely using polite form endings and in a gender-neutral manner. She notes that "strong masculine language, which is commonly used among young L1 Japanese men, is nearly absent in the textbooks and is often dismissed as "impolite" language in the classroom" (Iwasaki 2011, 98). Therefore, these educators' language ideology strongly inhibits learners' use of masculine forms.

What do these metapragmatic discourses about real life usage mean to this study? Can they explain why contemporary novelists do not assign masculine utterance-final forms to their non-Japanese male characters? One possibility is that the speech of fictional characters reflects that of real speakers. Non-Japanese individuals in real life are dissuaded to learn and use masculine language because textbooks do not present it and teachers discourage its use. They are also inhibited to use masculine language because of native speakers' negative reactions. To imitate these real speakers, novelists might assign gender-neutral language to male non-Japanese characters.

This might be the case to some extent. However, as Kinsui (2003) and others have pointed out, fiction tends not to replicate reality. It is more likely to reflect fiction creators' ideology. What ideology are novelists inclined to have with regards to masculine linguistic forms? Fukuda (2014), whose observation about a Mexican speaker and his Japanese conversational partner is mentioned above, discusses other similar studies such as Ohta (1993) and Iino (2006), which reports that Japanese host families do not use regional dialects and slang to guest foreign students. She concludes that many Japanese do not consider vernacular varieties, such as regional dialects, slang, and masculine language, to be part of the linguistic repertoire of non-Japanese, but solely that of Japanese. In discussing Rick's friends' reaction to his speech, Ohta (1993) also suggests that Rick's Japanese friends' attempts to prevent Rick from using masculine Japanese might have been a strategy for maintaining their linguistic distinctiveness.

Where does this idea that masculine language belongs exclusively to the Japanese come from? I would argue that this desire to protect linguistic distinctiveness comes from linguistic nationalism. McVeigh (2006) observes that many Japanese assume that only the Japanese own the Japanese language. This language ideology equates linguistic (and cultural) competence with ethnicity (“Japanese blood”). ${ }^{23}$ Niyekawa

23. Linguistic nationalism is part of a broader ideology of cultural nationalism which includes a belief on the exclusive ownership of Japanese culture (Yoshino 1992; McVeigh 2006). The language is at the core of the culture since it is "frequently regarded as the essential element in making the Japanese "Japanese"” (McVeigh 2006, 197). Linguistic nationalism in its contemporary form is a relatively recent ideology. The idea that the Japanese shared kanbun (Chinese classics and classical writing) with Chinese civilization was prevalent in the beginning of the Meiji period 
(1991, 24) observes: "many Japanese have a mystical belief in "blood," and feel that anybody who has Japanese blood flowing in his body should think, speak, and behave the Japanese way" (Niyekawa 1991, 24). Takamori $(2010,226)$ also critiques the assumption pervasive in Japan "that people with Japanese blood would be able to assimilate readily into Japanese society". Japanese Americans she interviewed mentioned that their Japanese language teachers expect Japanese American students to "naturally" possess more advanced proficiency than non-Japanese students because of their ethnicity.

This link between blood and Japaneseness suggests, conversely, that unless you are ethnically Japanese, you are not likely to speak or behave in the Japanese way. Creighton (1997) observed exactly this assumption. In her study of Japanese advertisements, Japanese advertisers present Caucasian models/actors as being inept at pursuing traditional Japanese arts or habits. She notes that the projections of these non-Japanese models/actors' awkwardness "with Japanese customs, or in using the Japanese language, reinforce a sense that there is something about these cultural identity markers that is solely for the Japanese" (Creighton 1997, 221). In her study of gaijin tarento 'foreign celebrities' in the 1980s in Japan, Miller $(1995,192)$ observes that speaking Japanese is considered to be "uncharacteristic behavior for foreigners and is marked as deviant or irregular."

One of the metapragmatic stereotypes observed by Yoda (2011) in her data of comic books and animation films, the stereotype of non-Japanese individuals speaking in broken Japanese, is an outright reflection of this linguistic nationalism. Because only the Japanese are supposed to speak the language perfectly, the speech of non-Japanese is uncritically represented as imperfect. As my data of contemporary novels are for adult consumption, such blatant stereotyping is not prevalent. There are abundant fluent non-Japanese characters in contemporary novels.

However, as mentioned above, vernacular varieties of Japanese, such as masculine Japanese and regional dialects, seem to belong to a set of linguistic resources available only to ethnically Japanese individuals. Doerr (2015) notes the relationship between the use of regional dialects and authenticity. She writes, "a "foreigner" who spoke a dialect of Japanese was considered more competent in Japanese, implying that a dialect was [...] more difficult, more authentic Japanese" (Doerr 2015, 398). Does this mean that masculine language is also considered to represent linguistic competence and authenticity?

(1986-1912), but the support for it began to waver in the late Meiji period (McVeigh 2006, 173). As the efforts to modernize Japan and establish its national identity including the construction of kokugo 'national language' (Yi 1996) took place in the Meiji period, the ideology that the Japanese exclusively possess kokugo became dominant. See Yoshino (1992, 1996), Befu (1993), Abe (2001), Kayama (2002), Komori (2003), McVeigh (2006), Iwabuchi (2007), Suzuki (2015) for more discussions on cultural/linguistic nationalism in Japan. 
Contemporary novelists whose work this study has examined seem to equate the use of masculine utterance-final forms with superior linguistic proficiency. As Tables 1 and 3 show, only 5 male characters are assigned masculine utterance-final forms when they speak in Japanese. The rest of the Japanese speaking male characters ( 32 of them) are portrayed speaking in a non-gendered manner. A close examination of these 5 exceptional cases reveals the novelists' association of masculine forms and linguistic competence. The following examples show that when a character uses masculine forms, the narrator of the novel often comments on the character's superior fluency in Japanese. The masculine forms are marked in bold while narrators' comments regarding fluency are underlined.

(9) "Ikenai ka? Koko wa kin'en-seki janai ze, hanii" good: NEG FP here TOP no.smoking-seat COP: NEG FP honey Chijireta akage no shita no me o kochira ni mukete, curly red:hair GEN under GEN eye ACC this.way to turn otto to yuu koto ni natteiru otoko wa ryuuchoo na husband QUOT say NMLZ to be man TOP fluent COP nihongo de oojiru.

Japanese with respond

"'You don't approve? This is not a non-smoking seat, honey?" A man who is supposed to be my husband responds in fluent Japanese while turning his eyes towards me from below his curly red hair.'

(Fukui 2002, 222)

(10) "Shiru ka. Benshooshiro." Kinsen $\underline{\text { ni }}$ karamu nihongo $\underline{n i} \underline{\text { wa }}$ know FP compensate finance with involve Japanese with TOP tsuyoi rashii bobu o mizuki wa tsutomete reiseini mitsumeta. strong seem <name> ACC <name> TOP try calmly look

"'Who cares. Pay up." (said Bob). Mizuki tried hard to look calmly at Bob, who seems to be good at Japanese when it comes to financial matters.'

(Yoshinaga 2011, 189)

(11) "Eigo de gomakashite $n$ janee zo." Andaason no English with trick NMLZ COP: NEG FP <name> GEN nihongo wa myooni ryuuchoo de kudaketeiru kara, okashii. Japanese TOP weirdly fluent COP casual so funny ' "Don't try to trick me with English." (said Anderson). Anderson's Japanese is weirdly fluent and casual, so it is funny'.

(Isaka 2008, 32-33)

In (9) the character utters a masculine particle $z e$. The narrator says that the character's utterance was "in fluent Japanese." In (10) the character uses a direct and rough imperative form benshoo shiro 'compensate; pay up. This is followed by the narrator's comment that the character's Japanese is good when it comes to financial matters. In (11) a character uses a masculine pronunciation janee (as opposed to 
the more conventional janai) and a masculine particle $z o$. The narrator immediately explains that the character's Japanese is "weirdly fluent and casual, so it is funny." 4 These comments suggest that the novelists equate the use of masculine Japanese with superlative linguistic competence.

Further, of the five characters who are assigned masculine forms when speaking Japanese, two are pretending to be Japanese, and one is a CIA agent. Of the two characters who are pretending to be Japanese, one is a North Korean spy. These backgrounds of the characters suggest that the authors imagine the use of masculine Japanese as a uniquely Japanese trait or as a resource only available to highly skilled individuals.

Thus, the novelists regard the use of masculine Japanese as a sign of exceptional linguistic proficiency, and assign it only to those characters who pretend to be Japanese or characters who, for professional purposes, are represented as possessing a highly skilled competence. As I mentioned earlier, only the Japanese can speak the language perfectly per linguistic nationalism. The mastery of masculine Japanese is considered to be only available to Japanese and a chosen few non-Japanese characters with special backgrounds. This accounts (at least partly) for the fact that the majority of male non-Japanese characters does not use masculine forms in contemporary fiction.

It seems rather odd that contemporary novelists so strongly equate the use of masculine forms with competence. As footnote 21 mentions, in real life some non-Japanese individuals who possess limited proficiency may use masculine language if they have contacts with working-class Japanese individuals. Also, if masculine language is so closely associated with superior fluency, why are language teachers discouraging it? Why aren't language textbooks promoting it?

Perhaps Doerr's (2015) characterization of regional dialects as a marker of authenticity is relevant here. Masculine expressions, along with regional dialects and slang, are considered to be authentically Japanese. Authenticity could be easily equated with superior knowledge and fluency. This might be why contemporary novelists whose work I examined assigned masculine utterance-final forms to only a chosen few with special backgrounds. When these characters used masculine forms, the novelists specifically mentioned their proficiency via the narrators' commentaries. However, authenticity might also mean that it is meant only for domestic consumption. Masculine expressions, as well as regional dialects and slang, are regarded as casual, friendly, impolite, and vulgar. These vernacular versions of Japanese are

24. This last comment that characterizes a character's fluency and casualness as being weird and funny supports Miller's (1995) observation that non-Japanese individuals' Japanese speaking ability is viewed as deviant or irregular. 
supposed to be only available to the insiders, i.e., the Japanese. This might be why language teachers and textbooks discourage the use of masculine Japanese because it is for insiders only. Whether it is interpreted to be a sign of superior linguistic competence or too unrefined to be presented to outsiders, masculine language is a symbol of authenticity and thus is subject to linguistic nationalism. The representations of male non-Japanese characters' speech reflect this language ideology.

\section{The norm of feminine language and non-Japanese characters}

What about the depiction of female non-Japanese characters?

When female speakers communicate in a language other than Japanese, their speech almost always ends with gendered forms ( $96 \%$ of the time). Of the 26 speakers, I only found one example in which a female character speaks without feminine utterance-final forms. The following are a few representative examples of the feminine form use. The utterance-final expressions associated with strong femininity are marked in bold.

(12) Kore wa rika, anata ni makasete ii no yo ne. [...] Kore this TOP <name> you with entrust ok NMLZ FP FP this mo anata ni doosekishite-morau wa. Senshuu kara itte-atta also you with sit.with-receive FP last:week from said-already wa yo ne. [...] Sorekara, kyoo wa isshoni ranchi demo FP FP FP and today TOP together lunch even doo kashira.

how wonder

'This project, I can entrust it with you, right, Rika? [...] For this project as well, I am going to have you sit at the meeting. I already told you so last week, didn't I? [...] And, how about lunch together today?

(Mori 2009, 260)

(13) Ara, hontooni koosoku testudoo ga hashiru no nee. [...] Kono oh really express railway NOM run NMLZ FP this koosoku tetsudoo ga dekitara, watashi, benri da wa. express railway NOM complete:COND I convenient COP FP [...] Watashi no inaka takao no inaka no I GEN hometown <name> GEN countryside GEN hoo na no yo.

direction COP NMLZ FP

'Oh, express trains are really going to run, aren't they? [...] It is going to be very convenient for me when the express railway is completed. [...] My hometown is in a countryside in Takao, you know?

(Yoshida 2012, 377) 
(14)

Okyaku no inai toki wa, hon o yondeitemo ii customer NOM exist:NEG time TOP book ACC be.reading.COND ok [...] no yo. Hadazamui wa ne.

NMLZ FP chilly FP FP

'You can read books when there are no customers, you know? [...] It is chilly, isn't it?'

(Ekuni 1999, 27)

An African American working for the United Nations Refugee Agency says (12) in English. A middle-aged café waiter in Taiwan utters (13) in Mandarin. An old Italian jewelry shop owner says (14) in Italian. Thus, regardless of race, occupation, age, and language, female characters speaking in a language other than Japanese are depicted using feminine utterance-final forms.

When female non-Japanese characters speak in Japanese, the use of gendered forms is less frequent at $56 \%$ of the time. The following are examples of the use and non-use of feminine forms when characters speak in Japanese.

(15) Soo. Aimai na no ne. Muzukashii wa. [...] Yoku shitteiru no so vague COP NMLZ FP difficult FP well know NMLZ ne. [...] Kaettekita toki roketto wa attta wa, zettaini. FP returning:come time locket TOP existed FP definitely 'Is that so. It is vague, isn't it? It is so hard. [...] You know so much about this, don't you? [...] When I came home, the locket was definitely here.'

(Yoshinaga 2013, 159)

(16) Haruka wa zenzen daijoobu yo. [...] Ato, aa miete Yamao $<$ name $>$ TOP perfectly fine $\mathrm{FP}$ and that look <name> bucho mo jitsu wa hada ni atteru no yo ne. Kibishii manager also actual TOP skin with match NMLZ FP FP hard no wa kibishii kedo, on to ofu no kirikae ga umai to NMLZ TOP hard but on and off GEN switch NOM good QUOT yuu ka, ne ga nonbirishiteiru no yo.

say FP root NOM laid.back NMLZ FP

'Haruka is perfectly fine. [...] And, Manager Yamamoto actually fits the job, even though he does not appear so. The job is hard, but he is good at balancing his work and rest, or I should say he is fundamentally a laid back person, you know?

(Yoshida 2012, 73-74)

(17) Watashitachi no dentoo wa soozoosareta mono desu. we GEN tradition TOP construct: PAss thing COP Watashitachi no kyoodootai wa soozoosareta mono desu. we GEN community TOP imagine: PASs thing COP Soredemo watashitachi wa, muttsu no bunka no doreka hitotsu even-so we TOP six GEN culture GEN which one 


ni de wa naku, watahitachi no bunka ni ikiru koto ni
in COP TOP NEG we
naru no desu.

'Our traditions have been constructed. Our communities have been imagined. Even so, we are destined to live in our (collective) culture, not in one of the six cultures.

(Yonezawa 2006, 143)

(18) Miu-chan no okaasan ga ryuugakusei datta koro, musuko $<$ name> GEN mother NOM foreign.student COP when son to totemo naka ga yokatta. Shuumatsu ni wa yoku futari with very relation NOM good weekend in TOP often two de kono ie ni asobini kimashita.

COP this house to visit came

'Miu, when your mother was a foreign student, she was very close to my son. On weekends, the two of them often came to this house for a visit.

(Nakajima 2012, 220)

In (15) a language teacher from Iran speaks fluent and feminine Japanese. So does an office worker in Taiwan in (16). On the other hand, in (17) a teen from Yugoslavia ${ }^{25}$ talks exclusively in formal forms, which are devoid of gender markings. The speaker of (18), an old woman in Taiwan, uses both formal and informal endings, but does not use any feminine utterance-final forms.

Why do the novelists assign feminine utterance-final forms only $56 \%$ of the time when female characters communicate in Japanese while they assign them $96 \%$ of the time when they speak another language? This contrast can be explained at least partly by the notion of linguistic nationalism delineated in the last section. If novelists (consciously or unconsciously) harbor the common sentiment that only the Japanese own the Japanese language, then the use of feminine utterance-final forms, which is considered to be uniquely Japanese by some scholars, ${ }^{26}$ may not be found in the Japanese speech of female non-Japanese characters at least some of the time. ${ }^{27}$ For example, the teen from Yugoslavia in (17) does not use any feminine

25. The story takes place in 1991 when the Socialist Federal Republic of Yugoslavia was disintegrating in the Yugoslav wars.

26. Kindaichi $(1942,293)$ writes, "Japanese women's language is so good that it seems to me that it is [...] unique in the world" (the translation is taken from Inoue 2004, 58).

27. In real life, non-Japanese individuals may choose to use or not use feminine forms for different reasons. Siegal (1994) reports that several white female learners she interviewed refused to use feminine language including honorific forms because they reject the hegemonic gender ideology. Iwasaki (2008) also notes that learners use their agency to choose certain linguistic forms regardless of their competence. This study, however, is examining how novels represent non-Japanese individuals. Since fictional characters do not have the agency, what matters is the novelists' language ideologies. 
forms while her Japanese friend's speech is casual and stereotypically feminine as shown in (19). The novelist clearly distinguishes the Yugoslavian teen's Japanese speech from the Japanese teen's.

(19) Demo, yokatta wa ne. Mochi no hanashi o shitenakattara, but good FP FP rice.cake GEN talk ACC did: NEG: COND tabun yama no naka de furareteita wa yo. maybe mountain GEN inside in rained: PASS FP FP 'But this is good. If we had not been talking about rice cakes, we might have been rained on in the mountain.'

(Yonezawa 2004, 162)

However, a more complex picture arises when you look at the numbers more closely. Even though the percentage of gendered utterance-final form assignment to female non-Japanese characters speaking in Japanese (56\%) is lower than the characters who speak in another language (96\%), the percentage is significantly higher than the percentage of gendered language use among male non-Japanese characters speaking in Japanese (14\%). It is exactly four times more often that female characters are assigned gendered utterance-final forms than male characters. Why do novelists treat female speech differently than male speech?

Regarding the differences between linguistic femininity and masculinity, Nakamura $(2007,2013)$ notes that feminine language does not simply refer to the language that people assume women use, but it represents the language people think women should use. On the other hand, people do not necessarily think that men should use masculine language. Nakamura $(2007,40)$ observes that young girls are often reprimanded for not using feminine language while boys are hardly ever scolded for not using masculine language. In other words, feminine language is normatively assigned to female speakers, while masculine language is not imposed upon male speakers.

The normative force of feminine language is so pervasive that it may not even be recognized as such. Nakamura (2013) examines how non-Japanese individuals' utterances are translated into Japanese in various media such as newspaper articles, television dramas and films, and notes that when women's speech is translated, it is likely to be translated into feminine Japanese. She attributes this to translators' belief that women always use feminine language. She observes that even when assertive female characters in film were introduced to Japanese audiences in the 1970s, their speech was reflexively translated into feminine Japanese because of such a firm and common belief in the predominance of feminine language. A similar argument can be made about the contemporary novel data in this study. If novelists share this belief/language ideology that women always use feminine forms, then they are likely to reflexively assign feminine forms to even female non-Japanese characters. This would explain both the extremely high percentage in which novelists assign 
feminine utterance-final forms to female characters when they speak another language as well as the relatively high percentage in which feminine utterance-final forms are given to female characters when they speak Japanese.

In addition, linguistic nationalism may not be as relevant to feminine forms of language as to masculine forms. In the last section we saw that masculine language represents authentic Japanese-ness that may be equated with superior linguistic proficiency and/or in-group status. Doesn't feminine language also represent authenticity? It does not seem to do so, at least not in the same manner. First, contemporary novelists examined in this study do not seem to equate feminine utterance-final forms with linguistic competence. There are several female characters whose Japanese speech is portrayed as incompetent and yet feminine. Examples in which feminine forms are marked in bold are shown below.

(20) Shiai mita wa. [...] Ashita wa aruzenchin ne. Tsuyosoo ne. game saw FP tomorrow TOP Argentine FP strong:look FP 'I saw the game. [...] Tomorrow you are up against Argentine, aren't you? They look strong, don't they?'

(Yata 2006, 148)

(21) Doo yuu imi kashira?

how say meaning wonder

'What do they mean, I wonder?'

(Yanagi 2012, 134)

(22) Boraaju, saa kore-kara yo.

$<$ name $>$ now this-from FP

'Borage, all starts now'.

(Miyamoto 1998, 403)

The speaker of (20) is an American high school student who has recently arrived in Japan. The narrator explicitly says that her Japanese is poor, and most of her utterances are written in katakana. ${ }^{28}$ Yet, she uses feminine forms at the end of many of her utterances. A woman from Belgium says (21), whose utterances are also written in katakana, using the super-feminine expression, kashira. The speaker of (22) is a French graduate student, whose Japanese is described in the novel as "not very good." She gives a long speech, the content of which is conveyed in the novel as indirect quotations. At the end of the speech, she says (22), which is the only direct quotation of her speech, and that ends with the feminine form. These examples suggest that the association between feminine language and linguistic competence is not as strong as that between masculine language and competence.

28. Katakana are orthographic symbols usually used to write Western loan words and onomatopoeic expressions. Non-conventional use of katakana can be interpreted in diverse ways (Hudson and Sakakibara 2007; Ezaki 2010), but in this context it seems to indicate non-conventional intonation or pronunciation. 
Further, as we saw in the last section regarding Examples (9), (10), and (11), when a male character uses masculine forms, the narrator of the novel often makes explicit comments about the character's linguistic competence. For example, in (11) when a character named Anderson uses masculine forms, the narrator of the novels says, “Anderson's Japanese is fluent and weirdly casual." However, such metapragmatic commentaries are absent when female speakers use feminine speech. Thus, female characters' use of feminine language is not considered to be something exceptional, but more of a norm. The novelists treat the feminine language use by female non-Japanese characters as an ordinary, unremarkable occurrence. This of course not only indicates the lack of connections between superior fluency and feminine language but also how impactful the normative force of feminine language is. The normativity of linguistic femininity is such that it undermines the possible link between feminine forms and proficiency.

Feminine language may also not evoke authenticity because it does not symbolize in-group status. As Oakamoto and Shibamoto Smith (2008) and others note, feminine language forms such as utterance-final forms discussed in this paper are often linked to politeness, gentleness, and refinement. These concepts are in complete opposition from the attributes associated with masculine language as well as regional dialects and slang (informality, friendliness, impoliteness, and vulgarity). Feminine language, therefore, does not belong to the vernacular varieties of Japanese that are considered to be only available to insiders. This may also explain why novelists assign feminine utterance-final forms more liberally than masculine utterance-final forms to non-Japanese characters, who are presumably considered to be outsiders.

\section{Concluding remarks}

The preceding sections illustrate how two types of language ideologies prevalent in Japan, linguistic nationalism and feminine language normativity, affect the representations of non-Japanese characters in contemporary Japanese novels.

As Kinsui (2003) and others point out, conversations in fiction are filled with stereotyped utterances and do not reflect reality. Fiction writers utilize stereotypes for multiple reasons, one of which is to evoke certain images that are associated with stereotyped speech. For example, Jorden $(1983,124)$ remarks, "Masculine language is a variety that communicates assertiveness, strength, toughness, and vigor". If masculine language does indeed bring up such images, it is unfortunate that contemporary novelists so rarely assign masculine language to their male non-Japanese characters. They significantly limit the portrayal of male non-Japanese characters as a result. Similarly, if feminine language imparts femininity, civility, grace, 
middle-age, and middle-class as Nakamura (2013) describes, it is rather unfortunate that such images are reflexively imposed upon female non-Japanese characters, limiting the multiplicity and gradations of characters.

With regard to linguistic nationalism, I was intrigued to find that it is more pertinent to linguistic masculinity than to linguistic femininity. That is, masculine forms are treated as the linguistic resources exclusively available to the Japanese more so than feminine forms. This is surprising because traditional scholars of Japanese have treated feminine expressions as "uniquely Japanese" (Kindaichi 1942, 293) and as "the cultural heritage passed down from the ancestors" (Mashimo $1969,81) .{ }^{29}$ Even though masculine language has not been treated as unique or of cultural value in the past, the language ideology surrounding it suggests that it is shielded from outsiders and that it is a precious linguistic resource meant only for insiders. This is an interesting paradox that future studies can explore.

\section{Acknowledgements}

I presented a shorter version of this paper at the 8th International Gender and Language Association Conference in Vancouver in 2014. I am grateful to Momoko Nakamura for inviting me to join the panel she organized and also for reading an earlier draft of this paper and giving me encouragement and suggestions for improving it. Thanks are also due to Cindi SturtzSreetharan, Neriko Doerr, Chie Fukuda and Rika Ito for giving me advice during different stages of writing. Lastly, I would like to thank the anonymous reviewers of this article for their invaluable suggestions. All errors are my own.

\section{Data references (The novels mentioned in the text are marked with an asterisk)}

Aoki, Jungo. 2011. Watashi no inai kookoo. Tokyo: Koodansha.

* Ekuni, Kaori. 1999. Reisei to joonetsu no aida - Rosso. Tokyo: Kadokawa Shoten.

* Ekuni, Kaori. 2013. Mahiru nanoni kurai heya. Tokyo: Koodansha.

* Fukui, Harutoshi. 2002. Bookoku no iijisu - Ge. Tokyo: Koodansha.

* Isaka, Kootaroo. 2008. Maoo. Tokyo: Kodansha.

Isaka, Kootaroo. 2009. Ahiru to kamo no koinrokkaa. Tokyo: Sogensha.

* Ishida, Ira. 2001. Ikebukuro uesuto geeto paaku. Tokyo: Bungei Shunjuu.

* Kakine, Ryoosuke. 2009. Yurikago de nemure - Joo. Tokyo: Chuuoo Kooron Shinsha.

* Kawataki, Kaori. 1993. Kokusai ren'ai zukan. Tokyo: Koosaidoo.

* Kondo, Fumie. 2010. Eden. Tokyo: Shinchoosha.

Makita, Mitsuharu. 2002. Trick Gekijoo ban. Tokyo: Kadokawa Shoten.

* Miyamoto, Teru. 1998. Suisei monogatari. Tokyo: Bungei Shunjuu.

29. The translation is taken from Inoue $(2004,58)$. 
Miura, Shion. 2006. Kaze ga tsuyoku fuiteiru. Tokyo: Shinchoosha.

* Mori, Eto. 2009. Kaze ni maiagaru biniiru shiito. Tokyo: Bungei Shunjuu.

Murakami, Haruki. 2004. Dansu, dansu, dansu - Ge. Tokyo: Kodansha.

Murakami, Ryuu. 1997. In za miso suupu. Tokyo: Yomiuri Shinbunsha.

* Murayama, Yuka. 2000. Ao no ferumaata. Tokyo: Shuueisha.

* Murayama, Yuka. 2012. Haruka naru mizu no oto. Tokyo: Shuueisha.

* Nakajima, Kyoko. 2012. Noronoro aruke. Tokyo: Bungei Shunjuu.

Nashiki, Kaho. 2001. Nishi no majo ga shinda. Tokyo: Shinchoosha.

Okuda, Hideo. 2002. Saiaku. Tokyo: Koodansha.

Shoji, Yukiya. 2008. Tokyo bando wagon. Tokyo: Shuueisha.

* Tsuji, Hitonari. 1999. Reisei to joonetsu no aida - Blue. Tokyo: Kadokawa Shoten.

* Tsuji, Hitonari. 2002. Sayonara itsuka. Tokyo: Gentoosha.

Yamada, Eimi. 1993. Chuuingamu. Tokyo: Kadokawa Shoten.

* Yanagi, Kooji. 2008. Jookaa geemu. Tokyo: Kadokawa Shoten.

* Yanagi, Kooji. 2012. Paradaisu rosuto. Tokyo: Kadokawa Shoten.

* Yata, Hiroo. 2006. Ore ga kinjo no kooen de rifuting shiteitara. Tokyo: Shoogakkan.

* Yonezawa, Honobu. 2004. Sayonara yoosei. Tokyo: Tokyo Sogensha.

* Yoshida, Shuuichi. 2012. Ruu. Tokyo: Bungei Shunjuu.

* Yoshinaga, Nao. 2011. Rantan tomoru madobe de. Tokyo: Tokyo Soogensha.

\section{References}

Abe, Hideko. 2010. Queer Japanese: Gender and Sexual Identities through Linguistic Practices. New York: Palgrave Macmillan. doi:10.1057/9780230106161

Abe, Kiyoshi. 2001. Samayoeru nashonarizumu: Orientarizumu, Japan, grōbarizēshon [Wandering nationalism: Orientalism, Japan, globalization]. Tokyo: Sekai Shisōsha.

Agha, Asif. 2004. "Registers of Language." In A Companion to Linguistic Anthropology, ed. by Alessandro Duranti, 23-45. Malden, MA: Blackwell.

Befu, Harumi. 1993. "Nationalism and Nihonjinron." In Cultural Nationalism in East Asia: Representation and Identity, ed. by Harumi Befu, 107-135. Berkeley: University of California Institute of East Asian Studies.

Bunkachoo, "Heisei 25 nendo 'kokugo ni kansuru yoron choosa' no kekka no gaiyoo [The outline of the results of 2013 "National Survey regarding national language"]." Accessed June 14, 2016. http://www.bunka.go.jp/tokei_hakusho_shuppan/tokeichosa/kokugo_yoronchosa/ pdf/h25_chosa_kekka.pdf

Burgess, Chris. 2010. “The 'Illusion' of Homogeneous Japan and National character: Discourse as a Tool to Transcend the 'Myth' vs. 'Reality' Binary." The Asia Pacific Journal 8 (9) (March): $1-23$.

Chinami, Kyoko. 2006. "Danwa sutoratejii toshite no gendaa hyooshiki [Gender markers as discourse strategies]." In Nihongo to jendaa [Japanese language and gender], ed. by Nihongo Gendaa Gakkai, 53-72. Tokyo: Hitsuji Shobo.

Chinami, Kyoko. 2010. "Manga: Gendaa hyoogen no tayoo na imi [Comics: Diverse meanings of gender expressions].” In Jendaa de manabu gengogaku [Linguistics learned from gender perspective], ed. by Momoko Nakamura, 73-88. Kyoto: Sekai Shiso-sha. 
Creighton, Millie R. 1997. “Soto Others and Uchi Others: Imaging Racial Diversity, Imagining Homogeneous Japan.” In Japan's Minorities: The Illusion of Homogeneity, ed. by Michael Weiner, 211-238. London: Routledge.

Doerr, Neriko M. 2015. "Standardization and Paradoxical Highlighting of Linguistic Diversity in Japan." Journal of Japanese Language and Literature 49 (2): 389-403.

Doerr, Neriko M., and Yuri Kumagai. 2014. "Race in Conflict with Heritage: "Black" Heritage Language Speaker of Japanese.” International Multilingual Research Journal 8: 87-103. doi: 10.1080/19313152.2013.825561

Ezaki, Motoko. 2010. "Strategic Deviations: The Role of Kanji in Contemporary Japanese." Japanese Language and Literature 44: 179-212.

Fukuda, Chie. 2014. "Identities and Linguistic Varieties in Japanese: An Analysis of Language Ideologies as Participants' Accomplishments." Pragmatics 24 (1): 35-62.

doi: 10.1075/prag.24.1.02fuk

Hagiwara, Shigeru, and Yoko Kunihiro (eds). 2004. Terebi to gaikoku no imeeji: Media sutereotaipingu kenkyuu [Television and images of foreign countries: Research on stereotyping]. Tokyo: Keiso Shobo.

Hambleton, Alexandra. 2011. "Reinforcing Identities? Non-Japanese Residents, Television and Cultural Nationalism in Japan." Contemporary Japan 23: 27-47. doi:10.1515/cj.2011.003

Hasegawa, Yoko. 2012. The Routledge Course in Japanese Translation. London: Routledge.

Hiramoto, Mie. 2009. "Slaves Speak Pseudo-Toohoku-ben: The Representation of Minorities in the Japanese Translation of Gone with the Wind." Journal of Sociolinguistics 13 (2): 249-263. doi: 10.1111/j.1467-9841.2009.00406.x

Hiramoto, Mie. 2010. "Anime and Intertextualities: Hegemonic Identities in Cowboy Bebop." Pragmatics and Society 1 (2): 234-256. doi:10.1075/ps.1.2.03hir

Hudson, Mutsuko E., and Yoshimi Sakakibara. 2007. "Emotivity of Nontraditional Katakana and Hiragana Usage in Japanese." In Applying Theory and Research to Learning Japanese as a Foreign Language, ed. by Masahiko Minami, 180-193. Newcastle upon Tyne: Cambridge Scholars Publishing.

Iino, Masakazu. 2006. "Norms of Interaction in a Japanese Homestay Setting: Toward a Two-way Flow of Linguistic and Cultural Resources." In Language Learners in Study Abroad Contexts, ed. by Margaret A. DuFon, and Eton Churchill, 151-173. Bristol, UK: Multilingual Matters.

Inoue, Miyako. 2003. "Speech without a Speaking Body: "Japanese Women's Language" in Translation." Language and Communication 23: 315-330. doi:10.1016/S0271-5309(03)00011-9 Inoue, Miyako. 2004. "Gender, Language, and Modernity: Toward an Effective History of “Japanese Women's Language."” In Japanese Language, Gender, and Ideology: Cultural Models and Real People, ed. by Shigeko Okamoto, and Janet S. Shibamoto Smith, 57-75. Oxford: Oxford University Press.

Inoue, Miyako. 2006. Vicarious Language: Gender and Linguistic Modernity in Japan. Berkeley, Los Angeles, London: University of California Press.

Irvine, Judith T. 1989. "When Talk Isn't Cheap: Language and Political Economy." American Ethnologist 16: 248-267. doi:10.1525/ae.1989.16.2.02a00040

Itakura, Hiroko. 2009. "Attitudes towards the Use of Masculine and Feminine Japanese among Foreign Professionals: What Can Learners Learn from Professionals?” Language, Culture and Curriculum 22 (1): 29-41. doi:10.1080/07908310802287681

Iwabuchi, Koichi. 2005. "Multinationalizing the Multicultural: The Commodification of 'Ordinary Foreign Residents' in a Japanese TV Talk Show." Japanese Studies 25 (2): 103-118. doi: 10.1080/10371390500225987 
Iwabuchi, Koichi. 2007. Bunka no taiwaryoku: Sofuto pawaa to burando-nashonarizumu o koete [Communicative power of culture: Beyond soft power and brand nationalism]. Tokyo: Nihon Keizai Shinbun Shuppansha.

Iwasaki, Noriko. 2008. "Style Shifts among Japanese Learners Before and After Study Abroad in Japan: Becoming Active Social Agents in Japanese." Applied Linguistics 31 (1): 45-71. doi: 10.1093/applin/amno47

Iwasaki, Noriko. 2011. "Learning L2 Japanese "Politeness" and "Impoliteness": Young American Men's Dilemmas during Study Abroad." Japanese Language and Literature 45 (1): 67-106.

Japan Book Publishers Association. “An Introduction to Publishing in Japan 2014-2015.” Accessed July 27, 2016. http://www.jbpa.or.jp/en/pdf/pdf01.pdf

Johnson, Sally, and Tommaso M. Milani (eds.). 2010. Language Ideologies and Media Discourse: Texts, Practices, Politics. London; New York: Continuum.

Jorden, Eleanor H. 1983. “Masculine Language." In Kodansha Encyclopedia of Japan, Vol. 5, 124-125. Tokyo: Kodansha.

Kadokawa Group Holdings Inc. "Kadokawa Annual Report 2012: The Platform to Produce Innovative Content.” Accessed July 27, 2016. http://ir.kadokawa.co.jp/ir/annual/2012/annual_2012.pdf

Kayama, Rika. 2002. Puchi nashonarizumu shookoogun [Petit nationalism syndrome]. Tokyo: Chuoo Kooron Shinsha.

Kindaichi, Kyosuke. 1942. Zooho kokugo kenkyuu [A study of national language, Additional supplement]. Tokyo: Yakumo Shorin.

Kinsui, Satoshi. 2003. Vaacharu nihongo: Yakuwarigo no nazo [Virtual Japanese: Mystery of role language]. Tokyo: Iwanami Shoten.

Kinsui, Satoshi. 2007. "Yakuwarigo toshite no pijin nihongo no rekishi sobyoo [The history of Pidgin Japanese as role language].” In Yakuwarigo kenkyuu no chihei [Horizon of role language study], ed. by Satoshi Kinsui, 193-210. Tokyo: Kuroshio Shuppan.

Kinsui, Satoshi. 2008. "Nihon manga ni okeru ijin kotoba [Foreigner talk in Japanese comics]." In Manga no naka no <tasha $>$ [<Others > within comics], ed. by Kimio Ito, 14-60. Kyoto: Nozomikawa Shoten.

Kinsui, Satoshi. 2014. "Fikushon no gengo to hoogen [Language in fiction and dialects]." In Dorama to hoogen no atarashii kankei: "Kaaneeshon" kara "Yae no sakura," soshite "Amachan" $e$ [The New relationship between dramas and dialects: From "Carnation" to "Double-flowered Cherry" to "Amachan”], ed. by Satoshi Kinsui, Yukari Tanaka, and Minako Okamuro, 11-21. Tokyo: Kasama Shoin.

Kroskrity, Paul V. 2004. "Language Ideologies." In A Companion to Linguistic Anthropology, ed. by Alessandro Duranti, 496-517. Malden, MA: Blackwell.

Komori, Yoichi. 2003. "Nihongo būmu to nashonarizumu [The Japanese language boom and nationalism]." Nihongo Kyooiku 116:1-4.

Kumagai, Shigeko. 2010. "Hoogen no rekishi: Wakai josei ga Toohoku hoogen o tsukainikui wake [The history of dialects: Why young women have difficulty using Tohoku dialect].” In Jendaa de manabu gengogaku [Linguistics learned from gender perspective], ed. by Momoko Nakamura, 50-65. Kyoto: Sekai Shisoo-sha.

Kumgai, Shigeko. 2016. "Who Speaks Tohoku Dialect? A Persistent Stigmatization of Tohoku Dialect in the NHK Morning Dramas." Paper presented at the 9th International Gender and Language Association Conference. 
Maree, Claire. 2008. "Grrrl-Queens: Onē-kotoba and the Negotiation of Heterosexist Gender Language Norms and Lesbo(homo)phobic Stereotypes in Japanese.” In AsiaPacifiQueer: Rethinking Genders and Sexualities, ed. by Fran Martin, Peter A. Jackson, Mark McLelland, and Audrey Yue, 67-84. Urbana: University of Illinois Press.

Mashimo, Saburo. 1969. Fujingo no kenkyuu [The Study of women's language]. Tokyo: Tokyodo Shuppan.

McVeigh, Brian J. 2006. Nationalisms of Japan: Managing and Mystifying Identity. Lanham: Rowman and Littlefield Publishers.

Miller, Laura. 1995. "Crossing Ethnolinguistic Boundaries: A Preliminary Look at the Gaijin Tarento in Japan.” In Asian Popular Culture, ed. by John A. Lent, 189-201. Boulder, CO: Westview Press.

Ministry of Justice (website), Accessed May, 2017 http://www.moj.go.jp/housei/toukei/toukei_ ichiran_touroku.html

Mizumoto, Terumi. 2006. “Terebi dorama to jisshakai ni okeru josei bunmatsushi shiyoo no zure ni miru jendaa firuta [Gender filter as seen in the differences of use in feminine utterance-final forms in TV dramas and real society]." In Nihongo to jendaa [Japanese language and gender], ed. by Nihongo Gendaa Gakkai, 73-94. Tokyo: Hitsuji Shoboo.

Mizumoto, Terumi. 2010. “Terebi Dorama: 'Dorama-go' toshite no 'onna kotoba' [TV Drama: 'Women's Language' as 'Drama Language"' In Gendaa de manabu gengogaku [Linguistics learned from gender perspective], ed. by Momoko Nakamura, 89-106. Tokyo.

Nakamura, Momoko. 2006. “Gengo ideorogii toshite no "onna kotoba”: Meiji-ki “jogakusei kotoba" no seiritsu ["Women's language" as language ideology: The formation of "female student speech" in the Meiji era]." In Nihongo to jendaa [Japanese Language and Gender], ed. by Nihongo Gendaa Gakkai, 121-138. Tokyo: Hitsuji Shoboo.

Nakamura, Momoko. 2007. <Sei> to nihongo: Kotoba ga tsukuru onna to otoko $[<$ Gender $>$ and Japanese language: Women and men that language creates]. Tokyo: Nihon Hoosoo Shuppan Kyookai.

Nakamura, Momoko. 2013. Honyaku ga tsukuru nihongo: Hiroin wa onnakotoba o hanashitsuzukeru [Japanese language that translation creates: Heroines continue to speak feminine language]. Tokyo: Hakutakusha.

Niyekawa, Agnes M. 1991. Minimum Essential Politeness: A Guide to the Japanese Honorific Language. Tokyo: Kodansha International.

Occhi, Debora J., Janet S. Shibamoto-Smith, and Cindi L. SturtzSreetharan. 2010. "Finding Mr. Right: New Looks at Gendered Modernity in Japanese Televised Romances." Japanese Studies 30 (3): 409-425. doi:10.1080/10371397.2010.518605

Ogawa, Naoko, and Janet S. Shibamoto Smith. 1997. "The Gendering of the Gay Male Sex Class in Japan: A Case Study Based on Rasen no Sobyoo." In Queerly Phrased: Language, Gender, and Sexuality, ed. by Anna Livia, and Kira Hall, 402-415. New York, Oxford: Oxford University Press.

Ohta, Amy S. 1993. “The Foreign Language Learner in Japanese Society: Successful Learners of Japanese Respond to Miller's "Law of Inverse Returns."” Journal of Association of Teachers of Japanese 27: 205-228. doi:10.2307/488925

Okamoto, Shigeko. 1995. ““Tasteless”Japanese: Less “feminine” Speech among Young Japanese Women.” In Gender Articulated, ed. by Kira Hall, and Mary Bucholtz, 296-325. New York: Routledge. 
Okamoto, Shigeko, and Shie Sato. 1992. "Less Feminine Speech among Young Japanese Females.” In Locating Power, ed. by Kira Hall, Mary Bucholtz, and Birch Moonwoman, 478-488. Berkeley: Berkeley Women and Lang. Group, Univ. of California.

Okamoto, Shigeko, and Janet S. Shibamoto Smith (eds.). 2004. Japanese Language, Gender, and Ideology: Cultural Models and Real People. Oxford: Oxford University Press.

Okamoto, Shigeko, and Janet S. Shibamoto Smith. 2008. "Constructing Linguistic Femininity in Contemporary Japan: Scholarly and Popular Representations." Gender and Language 2 (1): 87-112.

Okubo, Yuko. 2010. "Heritage: Owned or Assigned? The Cultural Politics of Teaching Heritage Language in Osaka, Japan." Critical Asian Studies 42 (1): 111-138. doi: $10.1080 / 14672710903537530$

Ota, Makie. 2011. "Usain boruto no "I" wa naze "ore" to yakusareru no ka : Supootsu Hoosoo no "yakuwari go" [Why is Usain Bolt's first person pronoun translated as "ore": "Role language" in sports broadcasting].” In Yakuwarigo kenkyuu no tenkai [Development of role language study], ed. by Satoshi Kinsui, 93-125. Tokyo: Kuroshio Shuppan.

Perkins, Chris. 2010. “The Banality of Boundaries: Performance of the Nation in a Japanese Television Comedy." Television and New Media 11 (5): 386-403. doi:10.1177/1527476409358087

"Public Libraries Are Thriving." Japan Times, November 18, 2012, accessed June 14, 2016. http://www. japantimes.co.jp/opinion/2012/11/18/editorials/public-libraries-are-thriving/\#.V2AoreYrKqC

Publishers Perspectives website. Accessed June 14, 2016. http://publishingperspectives.com/2016/ 05/idpf-alvin-lu-japan/\#.V2BgxuYrKqA

Sato, Shinji, and Neriko Doerr (eds). 2008. Bunka, kotoba, kyooiku:Nihongo/Nihon no kyooiku no "hyoojun" o koete [Culture, language, education: Beyond the "standard" of Japanese language/ Japan education]. Tokyo: Akashi Shoten.

Shibamoto Smith, Janet S. 2004. "Language and Gender in the (Hetero)romance: "Reading" the Ideal Hero/ine through Lovers' Dialogue in Japanese Romance Fiction." In Japanese Language, Gender, and Ideology: Cultural Models and Real People, ed. by Shigeoko Okamoto, and Janet S. Shibamoto Smith, 113-130. Oxford: Oxford University Press.

Shibamoto Smith, Janet S. 2005. "Translating True Love: Japanese Romance Fiction, Harlequinstyle.” In Gender, Sex and Translation: The Manipulation of Identities, ed. by Jose Sataemilia, 97-116. Manchester, U.K.: St. Jerome Publishing.

Shibamoto Smith, Janet S., and David L. Schmidt. 1996. "Variability in Written Japanese: Towards a Sociolinguistics of Script Choice." Visible Language 30 (1): 46-60.

Shibamoto Smith, Janet S., and Debra J. Occhi. 2009. “The Green Leaves of Love: Japanese Romantic Heroines, Authentic Femininity, and Dialect." Journal of Sociolinguistics 13 (4): 524-546. doi:10.1111/j.1467-9841.2009.00422.x

Siegal, Meryl. 1994. "Second-language Learning, Identity, and Resistance: White Women Studying Japanese in Japan." In Cultural Performances: Proceedings of the Third Berkeley Women and Language Conference, ed. by Mary Bucholtz, A. C. Liang, Laurel A. Sutton, and Caitlin Hines, 642-650. Berkeley, CA: Berkeley Women Language Group.

Sreetharan, Cindi S. 2004. "Students, Sarariiman (pl.), and Seniors: Japanese Men’s Use of 'Manly' Speech Register." Language in Society 33: 81-107. doi:10.1017/So047404504031045

SturtzSreetharan, Cindi S. 2015. "Na(a)n ya nen: Negotiating Language and Identity in the Kansai Region." Journal of Japanese Language and Literature 49 (2): 429-452.

Sugimoto, Yoshio. 2014. An Introduction to Japanese Society, Fourth Edition. Cambridge: Cambridge University Press. doi:10.1017/CBO9781107270107

Suzuki, Satoko. 2015. "Nationalism Lite?: The Commodification of Non-Japanese Speech in Japanese Media." Journal of Japanese Language and Literature 49 (2): 509-529. 
Takamori, Ayako. 2010. “Rethinking Japanese American 'Heritage' in the Homeland.” Critical Asian Studies 42 (2): 217-238. doi:10.1080/14672715.2010.486650

Takasaki, Midori. 2012. "Bimi o imi suru go no shiyoo to seisa [Use of words which indicate good flavor and gender differences].” Jinbun Kagaku Kenkyuu 8: 55-68.

Tanaka, Yukari. 2014. “"Amachan” ga hiraita atarashii tobira: "Hoogen kosupure dorama” ga dekiru made. [The new door that "Amachan" opened: The making of a "dialect costume play drama"]." In Dorama to hoogen no atarashii kankei: "Kaaneeshon" kara "Yae no sakura," soshite "Amachan" $e$ [The New relationship between dramas and dialects: From "Carnation" to "Double-flowered Cherry" to "Amachan"], ed. by Satoshi Kinsui, Yukari Tanaka, and Minako Okamuro, 22-43. Tokyo: Kasama Shoin.

Tsuneyoshi, Ryoko. 2004. “The 'New' Foreigners and the Social Reconstruction of Difference: The Cultural Diversification of Japanese Education." Comparative Education 40 (1): 55-81. doi: $10.1080 / 0305006042000184881$

UNESCO. "Literacy and Language Classes in Community Centers." Accessed July 27, 2016. http:// www.unesco.org/uil/litbase/?menu=14\&programme $=131$

Yano, Christine R. 2004. "Eyeing Nikkei: Portrayals of Japanese American on an NHK TV Drama." Paper presented at JAMCO 13th JAMCO Online International Symposium.

Yano, Christine R. 2010. "Becoming Prodigal Japanese: Portraits of Japanese Americans on Japanese Television." In Television, Japan, and Globalization, ed. by Mitsuhiro Yoshimoto, EvaTsai, and JungBong Choi, 217-239. Ann Arbor, MI: Center for Japanese Studies, University of Michigan.

Yoshino, Kosaku. 1992. Cultural Nationalism in Contemporary Japan. London and New York: Routledge.

Yoshino, Kosaku. 1996. Bunka nashonarizumu no shakaigaku: Gendai nihon no aidentiti no yukue [Sociology of cultural nationalism: Future of cotemporary Japan's identity]. Nagoya: Nagoya Daigaku Shuppankai.

Yi, Yŏn-suk. 1996. "Kokugo" to yuu shisoo: Gendai nihon no gengo ninshiki [The ideology of "national language": Language cognition in modern Japan]. Tokyo: Iwanami Shoten.

Yoda, Megumi. 2007. <Seiyoojingo> “Oo romio!" no bunkei: Sono kakuritsu to fukyuu [The style of <Westerner talk> "Oh, Romio!": Its establishment and popularization]. In Yakuwarigo kenkyuu no chihei [Horizon of Role Language Study], ed. by Satoshi Kinsui, 159-178. Tokyo: Kuroshio Shuppan.

Yoda, Megumi. 2011. "Yakuwarigo to shite no katakoto nihongo: Seiyoojin kyarakuta o chuushin ni [Broken Japanese as role language: Focus on Western characters]." In Yakuwarigo kenkyuu no tenkai [Development of role language study], ed. by Satoshi Kinsui, 213-248. Tokyo: Kuroshio Shuppan.

\title{
Author's address
}

\author{
Satoko Suzuki \\ Macalester College \\ Macalester University, United States \\ 1600 Grand Avenue \\ St. Paul, MN 55105 \\ United States \\ suzuki@macalester.edu
}


